\title{
SILWeb - analisador fonológico silábico-acentual de texto escrito
}

\author{
SILWeb - syllabic-accentual phonological parser of \\ written texts
}

\author{
Ana Cristina Fricke Matte \\ Universidade Federal de Minas Gerais \\ Alexsandro Meireles \\ Unicamp \\ Cecílio Cosac Fráguas \\ Unicamp
}

\section{Abstract}

This paper introduces the SilWeb software and discusses its design, which is notable for being the result of cooperation among linguists and engineers. Because of this, our development proceeds in two parallel tracks: a Mattosian study of our automatic phonological transcription and of the software algorithm. Both studies are reported here.

Keywords

Computacional linguistics, Phonology, Syllable, Text processing, Programming

\section{Resumo}

Este artigo apresenta o programa SilWeb - um programa analisador de texto escrito cuja finalidade é obter informações lexicais sobre acento e tipo de unidade fonológica -, e discute o processo de sua elaboração, cuja peculiaridade foi ser o resultado de uma interação entre lingüistas e engenheiros. Em função dessa 
interação, o processo contou com um estudo mattosiano da estrutura da transcrição fonológica adotada, bem como contou com o algoritmo do programa. Ambos os estudos estão relatados no presente artigo. Além da separação silábica tradicional, o programa possui uma versão para separação de unidades vogal a vogal.

\section{Palavras-chave}

Lingüística computacional, Fonologia, Sílaba, Processamento de texto, Programação. 


\section{INTRODUÇÃO}

7 orna-se cada vez mais comum a busca pela automação de determinadas análises lingüísticas. A ferramenta de revisão do

1 Microsoft Word, por exemplo, utiliza esse recurso para realizar sua tarefa de verificar a pertinência das construções sintáticas do usuário. O uso dessas ferramentas torna-se imperativo quando se trata de manipular extensos bancos de dados lingüísticos. O trabalho de construção dessas ferramentas depende de interação interdisciplinar, no caso entre lingüistas e engenheiros de computação, pois o conhecimento lingüístico permite a formulação das regras de análise a serem traduzidas para uma linguagem de programação.

O SilWeb foi uma ferramenta computacional que nasceu no âmbito do projeto temático "Integrando Parâmetros Contínuos e Discretos em Modelos do Conhecimento Fônico e Lexical", desenvolvido no Laboratório de Fonética e Psicolingüística (LAFAPE), Unicamp, a partir da necessidade de análise de dados do banco de texto escrito do CETEN/FOLHA, que é um arquivo de texto com uma análise e classificação palavra por palavra do jornal Folha de São Paulo. O SilWeb depende de uma prévia transcrição fonológica, fornecida pelo programa Ortofon (Albano \& Moreira, 1996), o que também permite que as buscas no banco de dados sejam providas de síntese de fala pelo programa Aiuruetê, baseado na transcrição do Ortofon. Em linhas gerais, o programa SilWeb consiste numa ferramenta para o sistema de buscas no banco de dados, possibilitando a busca por máscaras (consoante, vogal e semivogal), bem como determinando a posição do acento lexical na palavra e o número de sílabas. Desse modo, o pesquisador pode, por exemplo, recuperar uma lista de palavras em português que contenha a estrutura [paroxítona, 3 sílabas, VCCaCV], em que "a" representa uma vogal específica e CV 
consoantes e vogais quaisquer, resultando em palavras como "almaço" ou "armada". Sua integração ao Ortofon e ao Aiuruetê permite aos usuários, além dos resultados de suas buscas, a possibilidade de escutar uma síntese das palavras listadas.

\section{BREVE HISTÓRICO}

Os programas que precederam o SilWeb no âmbito do citado projeto, ou seja, o Listas e o próprio Ortofon, contaram com anos de pesquisas fonológicas também coordenadas por Eleonora Albano. Ambos contam com enormes listas de excessões relativas a regras até então não obtidas, além de algumas exceções inevitáveis. Além disso, como a programação foi realizada sem interação direta com o trabalho lingüístico, sua organização interna peca pela redundância de condições e regras. Contudo, seu funcionamento é eficiente e, por esse motivo, ambos os programas têm sido largamente utilizados pelos pesquisadores envolvidos.

O SilWeb foi concebido como uma ferramenta auxiliar para analisar a representação fonológica e possibilitar uma busca por tonicidade silábica e classificação acentual da palavra. A equipe discutiu o problema a partir da transcrição fonológica fornecida pelo Ortofon, pois essa transcrição é baseada em uma constituição silábica que identificamos com a orientação estruturalista, cujo principal nome no Brasil é Joaquim Mattoso Câmara Jr. (Cf. BISOL, 1996; CAGLIARI, 1999; CALLOU, 1990; CRISTÓFARO-SILVA, 1999). O padrão de transcrição utilizado pelo Ortofon distingue consoantes de início de sílaba das consoantes de coda silábica, facilitando a análise computacional com vistas à divisão silábica, ponto de partida da análise provida pelo SilWeb. O primeiro trabalho dos pesquisadores do SilWeb foi verificar essa identidade e explorar sua potencialidade.

Além disso, o grupo preocupou-se com a escolha da linguagem de programação utilizada, a fim de permitir a atualização constante do programa. Essa preocupação centrou-se em duas facetas: a nomenclatura das variáveis, que deveria ser de fácil entendimento a 
qualquer programador ou lingüista, e a própria linguagem de programação, que deveria propiciar rapidez no processamento, rápida implementação, além de possibilitar o uso de uma interface padrão via Web.

Após a conclusão do projeto temático, o SilWeb foi adaptado à unidade $\mathrm{V}-\mathrm{V}$. Essa unidade está baseada no conceito de P-center (MARCUS, 1981) e vai do início de uma vogal ao início da próxima. Estudos recentes para o francês, o inglês e para o portugüês indicam essa unidade como a de maior estabilidade, no que concerne à duração (BARBOSA, 1996), além de ser mais próxima da divisão perceptível do sinal de fala. Essa nova versão do programa foi chamada de SilWebVV.

Este artigo apresenta a história da programação do SilWeb: como, a partir de um classificador acentual, obtivemos um único programa capaz de fornecer máscaras de consoante e vogal (CV) com ou sem distinção de semivogais e a divisão em unidades V-V. Discutiremos também a propriedade da análise fonológica estruturalista para fins computacionais e as vantagens e desvantagens para analisadores lingüísticos de cada linguagem computacional experimentada.

\section{PROGRAMA: DECISÕES LINGÜÍSTICAS}

A tarefa de separar sílabas e de identificar consoantes e vogais pode parecer óbvia e simples para um ser humano letrado, mas exige conhecimento de suas regras para permitir a automação dessa tarefa. Podemos optar por duas vias de obtenção de tais regras: (i) observação de um vasto corpus que possibilite retornar regras compreensíveis para a máquina, ou (ii) conhecimento sobre o funcionamento da língua, cientificamente adquirido. Ambas as vias podem chegar a resultados confiáveis do ponto de vista estatístico, mas, com a devida cautela, pode-se afirmar que a segunda é capaz de retornar diretamente um conhecimento aplicável na própria ciência lingüística, enquanto a primeira será mais rapidamente assimilável no campo das aplicações práticas. Como o presente trabalho teve a preocupação de ser um 
instrumento lingüístico-científico, optou-se pela segunda via de trabalho.

O primeiro resultado prático dessa opção foi a discussão a respeito do tipo de escrita de entrada para um analisador silábicoacentual, ou seja, ortográfica, fonológica ou fonética. Embora a escrita ortográfica seja a mais acessível à totalidade dos pesquisadores, do ponto de vista fonético-fonológico ela não é adequada, visto que, para tal tipo de análise, são necessárias distinções sonoras no léxico mais precisas. Considere-se que nos dicionários eletrônicos Aurélio e Houaiss não há a possibilidade de buscar, por exemplo, somente palavras proparoxítonas, informações muitas vezes necessárias a certos desenhos experimentais. A escrita fonética seria, do ponto de vista computacional, a mais pertinente por ser mais específica a cada caso e, portanto, por princípio, aquela com as regras menos vulneráveis na relação escrita/fala. Um aplicativo não teria o menor problema em manipular os caracteres do Alfabeto Fonético Internacional (IPA), contemplados pelo código ASCII, mas, do ponto de vista lingüístico, seria uma incoerência completa fazer uma transcrição IPA de um corpus escrito e não falado. Essa restrição devese à ampla gama de possibilidades de realização de um mesmo fonema, que não depende somente de fatores intrínsecos como o contexto fonológico, mas também de fatores extrínsecos como o dialeto e as características pessoais do falante.

O IPA propõe transformar em caracteres distinções entre produções de fala que não produzem diferenças de sentido, no máximo distinguindo dialetos. Por exemplo, o /d/, que é fonologicamente o mesmo em qualquer dialeto brasileiro, pode ser produzido como africada em algumas regiões quando seguido de /i/, como em "dizer", e como oclusiva em outras, no mesmo contexto. O Ortofon, que realiza uma transcrição fonológica, vai representar esse fonema como "d" em qualquer situação.

Sendo assim, embora a transcrição fonética pudesse representar uma comodidade até para o pesquisador, consistiria, a rigor, em uma arbitrariedade insustentável do ponto de vista científico. Assim, a 
escrita adequada para tal análise seria, sem dúvida, uma transcrição fonológica feita a partir da escrita ortográfica, tal como aquela proposta pelo Ortofon. Cabe notar que o programa SilWeb foi concebido para ser usado em conjunto com o Ortofon, estando prevista sua disponibilização online já com a opção de entrada pela escrita ortográfica e conversão automática pelo Ortofon, possibilitando, além disso, síntese com o programa Aiuruetê, que foi baseado na escrita do Ortofon.

Diversos fatores contribuíram para a decisão de se trabalhar com a escrita fonológica obtida a partir do Ortofon durante a etapa de preparo do SilWeb silábico. Dentre elas, cabe destacar: (i) a possibilidade de automatizar a transcrição fonológica da escrita ortográfica: o Ortofon foi um programa desenvolvido com essa finalidade (ALBANO \& MOREIRA, 1996) e consiste em um conjunto de regras e exceções que abarcam a complexidade da relação entre o texto escrito e o texto falado, de modo a compreender a maleabilidade das regras, que identificamos com o uso do conceito de arquifonema de Joaquim Mattoso Câmara (retornaremos com detalhes sobre essa transcrição no tópico correspondente); e (ii) a interface com o Aiuruetê, um programa de síntese de fala desenvolvido na Unicamp numa cooperação entre a Lingüística e a Engenharia Elétrica. O objetivo desse programa é a leitura automática em voz alta de textos escritos, o que é feito pela identificação de fonemas pelo processamento com o programa Ortofon. Sendo assim, essa interface permitirá recuperar, como aplicação do banco de dados ou em outras aplicações, uma execução de fala sintetizada a partir dos mesmos dados obtidos pelo SilWeb.

Tomada essa decisão, o ponto de partida para a construção do SilWeb foi a identificação das sílabas a partir da escrita Ortofon. O trabalho começou com questionamentos a respeito dos caracteres iniciais e finais das sílabas e sobre o número de caracteres máximo por sílaba. Durante o estudo dessas regras, iniciou-se um trabalho de design baseado nos conceitos da orientação a Objetos, utilizando como linguagem de documentação o UML (http://www.rau-tu.unicamp.br/ uml/). Por simplicidade, não foi utilizada para a implementação uma 
linguagem orientada a objetos, mas este tipo de análise permitiu desenhar a arquitetura do programa, formulando com maior economia as regras relativas tanto à separação silábica quanto a todas as outras análises que o programa realiza, além de facilitar a comunicação entre os engenheiros e lingüistas.

O Ortofon possui algumas opções para a escrita das palavras. Para o SilWeb, optamos pelo seguinte padrão: a) marcar tônicas (o apóstrofo é necessário para a análise da acentuação); b) fechar o "e" final e o "o" final (embora não afete a análise pelo programa, esse padrão é comum à maioria dos dialetos brasileiros); c) não quebrar encontros consonantais (a silabificação da consoante surda é questionável e muitas vezes inapropriada pela curta duração do segmento, constituindo um problema do campo da fonética); d) não mudar o "l" após vogal e antes de consoante para "U" (permanece como arqui-segmento "L"); e) não mudar "nh" e "lh" para "ni"e "li"; f) fechar "e" e "o" em monossílabos átonos (padrão comum à maioria dos dialetos brasileiros); g) não reduzir "a” átono em monossílabos (permitirá, quando da análise de textos, a correta análise dessas sílabas como pretônicas).

As funcionalidades envolvidas no SilWeb podem ser organizadas segundo as funções específicas que ele executa. As funcionalidades do SilWeb são: a) verificar o tamanho da palavra; b) recuperar cada caractere da palavra para análise; c) verificar os finais de sílabas da palavra; d) recuperar e retornar cada sílaba; e) verificar a qualidade dos caracteres segundo sejam consoantes, vogais ou semivogais para cada sílaba; f) retornar a tonicidade da sílaba; g) retornar o número de sílabas na palavra; $h$ ) retornar a classe acentual da palavra conforme seja oxítona, paroxítona ou proparoxítona; i) retornar as máscaras 1 e 2, a primeira sem, e a segunda com distinção entre vogais e semivogais. O diagrama 1 organiza a aplicação desses métodos. Estas funcionalidades, por estarem pensadas (projetadas) e programadas separadamente, podem ser recombinadas conforme a necessidade do lingüista. Foi exatamente o que fizemos para transformar o SilWeb no SilWebVV. 


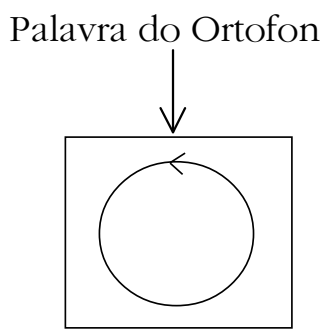

- número de sílabas

- classe acentual

- cada sílaba

$$
\begin{aligned}
& \text { _ tonicidade } \\
& \text { - máscara } 1 \\
& \text { - máscara } 2
\end{aligned}
$$

Diagrama 1: Aplicação do SilWeb
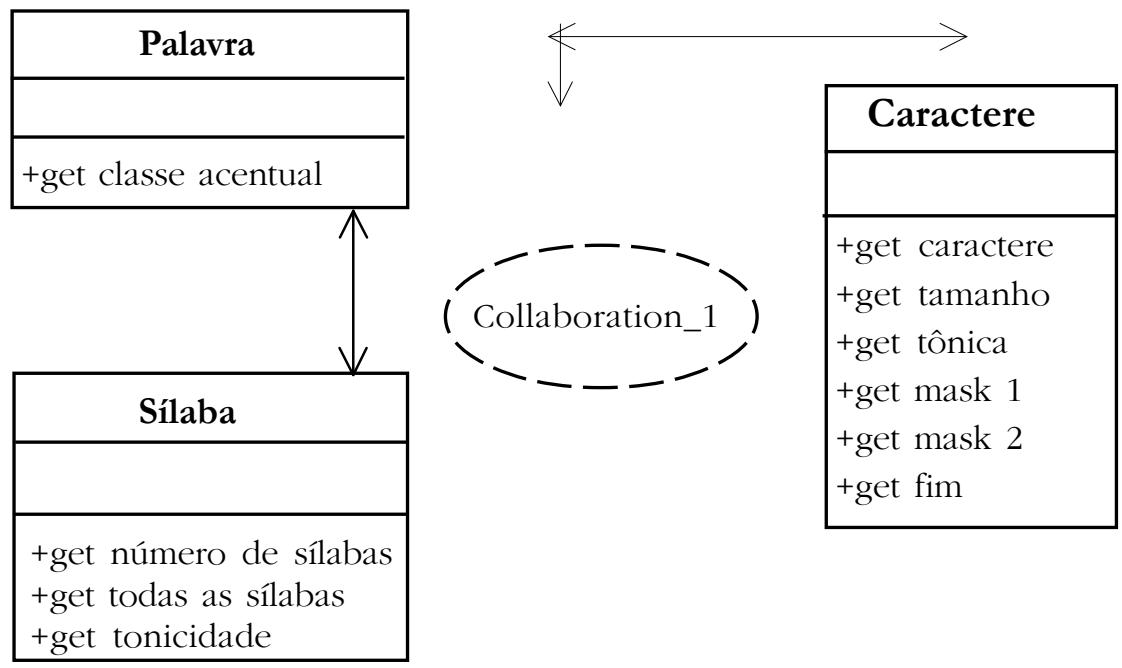

Diagrama 2: Diagrama de classes do programa SilWeb

O programa SilWeb pode ser organizado a partir de três entidades principais: a palavra, a sílaba e o caractere. Para cada uma dessas entidades associam-se tarefas específicas e o resultado final 
depende da interação entre elas, como pode ser observado no diagrama 2.

A entidade palavra realiza a tarefa de obter a classe acentual da palavra de entrada, seja ela oxítona, paroxítona ou proparoxítona (no diagrama, getClasseAacentual). Essa é a única tarefa realizada no âmbito da palavra. Todas as outras tarefas realizadas pelo programa o fazem com foco na sílaba ou no caractere.

Mais importante que isso é notar que a tarefa realizada no âmbito da palavra depende de outras tarefas que são realizadas no âmbito da sílaba ou do caractere. Para obter a classe acentual é preciso saber o número (getNúmeroDeSílabas) e a posição das sílabas, o que significa obter todas as sílabas em seqüência (getTodasAsSílabas), e a tonicidade de cada uma (getTonicidade), tarefas realizadas no âmbito da sílaba. Todas essas tarefas dependem de análises realizadas pela classe dos caracteres: a separação das sílabas para contagem e obtenção qualitativa das mesmas depende de uma análise posicional (getFim para a sílaba e getTamanho para a palavra) e qualitativa dos caracteres (getCaractere e getMask2, que já consiste numa análise) e a análise da tonicidade da sílaba depende da presença em seu interior de um caractere especial que indica que a sílaba é tônica (lexicalmente acentuada) (getTônica). Observe que tal marca advém da análise pelo Ortofon e não está necessariamente vinculada à presença do acento gráfico na forma ortográfica da palavra.

O diagrama 3 mostra a relação cronológica de tais tarefas no programa. A partir da análise desse diagrama, foi possível averiguar a possibilidade de retornar, além da informação sobre classe acentual da palavra e tonicidade das sílabas (pretensão original dessa programação), também as máscaras com ou sem distinção de semivogal, assim como informações sobre número de sílabas na palavra. 


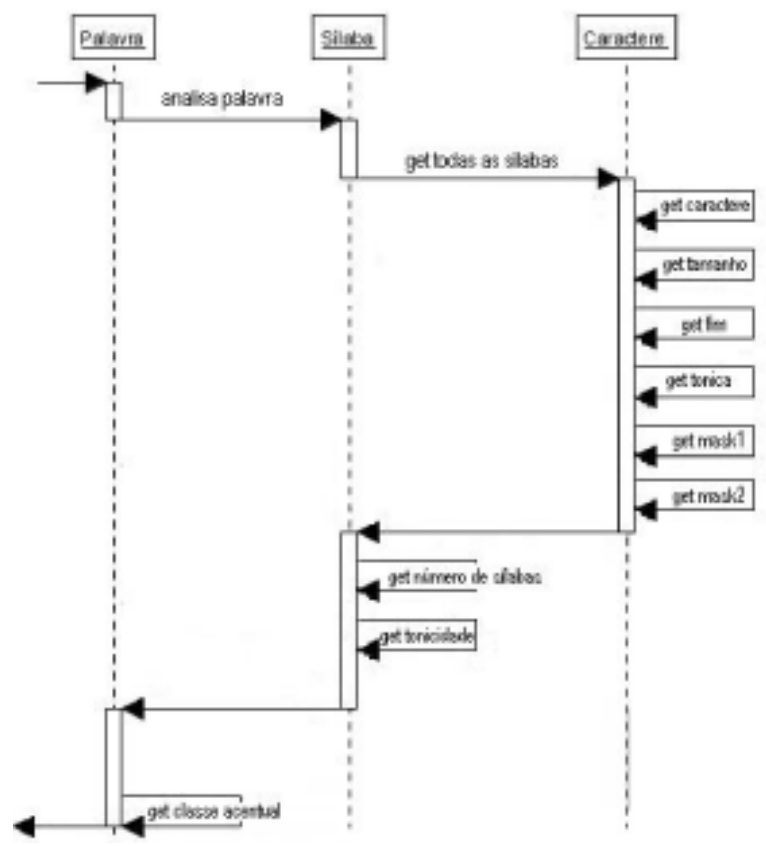

Diagrama 3: Diagrama seqüencial do SilWeb

O SilWeb atualmente está sendo utilizado no Banco de Aplicações Web do LAFAPE e funciona como programa auxiliar para a definição de buscas. É por meio de sua utilização que se pode varrer o corpus à procura de palavras contendo seqüências de consoantes e vogais pré-definidas ou não, palavras com determinada classe acentual, sílabas com determinada tonicidade, palavras com determinado número de sílabas, etc.

\section{ANÁLISE FONOLÓGICA}

O programa SilWeb foi criado a partir de uma teoria lingüística clássica da sílaba que diz que as vogais formam o centro sonoro da sílaba. Tal teoria tem como um de seus precursores o lingüista dinamarquês Otto Jespersen, o qual, em seu trabalho de 1904, expôs 
os pilares da referida teoria. Joaquim Mattoso Câmara Jr., um dos maiores expoentes da lingüística brasileira, fez a aplicação dessa teoria ao português, como podemos observar em sua obra clássica de 1970, publicada post-mortem - Estrutura da Língua Portuguesa. Nossa análise lingüística baseia-se, principalmente, nos princípios ali introduzidos.

De acordo com Mattoso Câmara Jr. ([1970]1982, 53-61), todas as consoantes portuguesas podem aparecer no aclive de uma sílaba, ou seja, na sua margem crescente, mas apenas algumas ocorrem no declive, ou margem decrescente e, quando isso se verifica, elas travam a sílaba. Destacou, ainda, o fato de as sílabas travadas, ou fechadas, serem muito menos freqüentes (apenas os arquifonemas R, S, L e N podem travar sílaba) do que as não travadas, uma vez que o padrão silábico de mais alta freqüência e de distribuição regular no português é o CV (consoante-vogal).

Esquematicamente, a sílaba pode ser representada por:

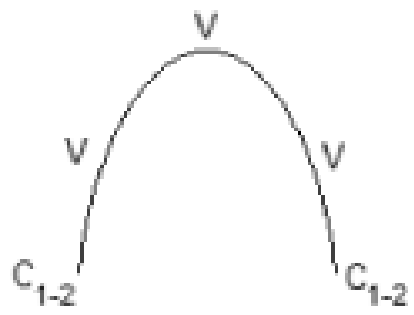

Figura 1: Esquema da sílaba em PB

Conforme a figura 1, a sílaba fonológica do português brasileiro pode ter um tamanho máximo de seis fonemas, ou seja: $\mathrm{C}_{0-2} \mathrm{~V}_{1-2} \mathrm{C}_{0-2}$, em que o único fonema obrigatório é o ápice da silaba (núcleo silábico). $\mathrm{O}$ aclive (ataque silábico) pode ser formado por uma (ataque simples) ou duas consoantes (ataque complexo) e ainda por uma segunda vogal, a qual é realizada foneticamente como uma semivogal (ditongo crescente). Da mesma forma, o declive (coda silábica) é formado também por uma vogal, realizada foneticamente como uma semivogal (ditongo decrescente), e por uma ou duas consoantes (sílabas fechadas). 
Outros dados lingüísticos utilizados na formulação de nosso algoritmo computacional foram as restrições fonotáticas do português em relação a determinadas posições silábicas, ou seja: 1) se houver um ataque complexo, a segunda consoante tem de ser, obrigatoriamente, /1/ ou /R/; 2) se a sílaba for fechada, as principais consoantes que podem travar a sílaba são os arquifonemas /R, S, L, N/; 3); se ocorrem duas consoantes em coda, a segunda, obrigatoriamente, tem de ser o arquifonema nasal /S/.

Para exemplificação de alguns possíveis tipos de sílabas no português brasileiro, observamos os dados no quadro 1, em que V é vogal e C consoante:

QUADRO 1

\begin{tabular}{|l|l|}
\hline $\mathrm{V}$ - /a, o/; & $\mathrm{V} \mathrm{C}-$ /as, oS/; \\
\hline V C V C - /aNUS/; & C V - /peh, ma, la/; \\
\hline C V C - /pehS, maR/; & C V C C - /teNS, peRSpeKtivA/; \\
\hline C C V - /gRavE, palavRA/; & C C V C - /kRuS/; \\
\hline C C V C V - / tReNI/; & \\
\hline C V V - /sabIO/. & \\
\hline
\end{tabular}

A partir da análise da escrita no Ortofon, obteve-se (a) a estrutura da sílaba quanto aos caracteres que a podem compor e (b) a seqüência da análise dos caracteres para (i) determinar o final da sílaba CV e recuperar cada uma, (ii) determinar para cada sílaba se é tônica e a tonicidade relativa à posição da sílaba na palavra e (iii) determinar a máscara CV, ou seja, a constituição da sílaba quanto ao número e posição de consoantes e vogais, e, finalmente, a máscara CVS, que é a máscara CV distinguindo semivogais.

Resumidamente, podemos demonstrar a análise feita pelo SilWeb em duas partes: (i) Sílaba no Ortofon: $\mathrm{C}_{0-2} \mathrm{~V}_{1} \mathrm{~V}_{0-1} \mathrm{C}_{0-2} \mathrm{~V}_{0-1} \mathrm{C}_{0-1}$ e (ii) Regras: algoritmo seqüencial de análise dos componentes; a cada análise positiva, inclui como componente e classifica máscara e tonicidade. 
Deve-se distinguir entre o tamanho máximo da sílaba em português (seis componentes) e o tamanho máximo virtual da sílaba, que considera as posições possíveis dentro da sílaba para consoantes, vogais e semivogais, notando-se que as semivogais estão incluídas no conjunto das vogais.

A sílaba foi pensada segundo a estrutura ataque-núcleo-coda, sendo o núcleo sempre uma vogal. Diferentemente do que ocorre na fonologia, em caso de ditongo crescente, por exemplo, em que a primeira vogal seria acrescentada ao início da sílaba junto com as consoantes iniciais, para fins de análise pelo programa optou-se por analisar o ditongo como um desdobramento do núcleo silábico.

A possibilidade máxima virtual da sílaba no Ortofon contém sete componentes: $\mathrm{C}_{\mathrm{a}} \mathrm{C}_{\mathrm{b}} \mathrm{V}_{\mathrm{c}} \mathrm{V}_{\mathrm{d}} \mathrm{C}_{\mathrm{e}} \mathrm{C}_{\mathrm{f}} \mathrm{V}_{\mathrm{g}} \mathrm{C}_{\mathrm{h}}$. Cada componente pode corresponder de 0 a 3 caracteres, incluindo-se marca de vogal aberta ou fechada e marca de sonoridade nas fricativas (em ambos os casos, a marca corresponde à letra "h") e marca de tonicidade (o apóstrofo simples segue as vogais tônicas). Nas consoantes, a sonoridade das fricativas é marcada pelo acréscimo do "h" à letra que corresponde ao par desvozeado (por exemplo, corresponde a /zh/, como em "já"), enquanto nas vogais o "h" marca a oposição entre fechadas (/e/, como em "feliz") e abertas (/eh/, como em "férias"). Outro caractere que pode ser acrescentado a um componente vocálico é a marca de tônica, do que decorre a possibilidade de três caracteres para um componente silábico. Cabe notar, no entanto, que a possibilidade máxima virtual da sílaba não corresponde à maior sílaba real encontrada, já que alguns componentes não ocorrem simultaneamente, o que pode ser mais bem compreendido pelas regras apresentadas a seguir.

As regras que orientam a análise feita pelo programa são:

a) Ataque silábico $\left(\mathrm{C}_{\mathrm{a}} \rightarrow\right.$ se o caractere for consoante e $\mathrm{C}_{\mathrm{b}} \rightarrow$ se for consoante e não ' $h$ ');

b) Máscara da primeira vogal $\left(\mathrm{V}_{\mathrm{c}} \rightarrow\right.$ analisa se a vogal é plena ou reduzida);

c) Ditongo crescente ou tritongo $\left(\mathrm{V}_{\mathrm{d}} \rightarrow\right.$ regra para ditongos: permanece na mesma sílaba se a vogal anterior não for reduzida); 
d) Regra para vogais abertas (inclui o caractere "h" na sílaba sem contar novo componente);

e) Regra da vogal acentuada (verifica a presença da marca de tônica: “" e a inclui sem contar novo componente);

f) Regra da vogal nasal $\left(\mathrm{C}_{\mathrm{e}}\right)$;

g) Regra dos arqui-segmentos $\left(\mathrm{C}_{\mathrm{e}}\right)$;

h) Regra da consoante de coda $\left(\mathrm{C}_{\text {e ou }}\right.$ );

i) Regra de ditongo com componente nasal ou tritongo, componente vocálico final $\left(\mathrm{S}_{\mathrm{g}}\right)$; e

j) Regra de consoante de coda em fim de palavra $\left(\mathrm{C}_{\mathrm{f} \mathrm{ou} \mathrm{h}}\right)$.

$\mathrm{O} \mathrm{V}_{\mathrm{c}}$ é o único caractere obrigatório na sílaba, pois corresponde ao núcleo. $\mathrm{O} \mathrm{V}_{\mathrm{d}}$ só aparece em ditongos e só será considerado desdobramento do núcleo se antecedido por uma semivogal. Em todo caso, para o programa não faz diferença se o núcleo silábico é $\mathrm{V}_{\mathrm{c}}$ ou $\mathrm{V}_{\mathrm{d}}$. O SilWeb trata somente as consoantes iniciais como início de sílaba, reservando para a posição $\mathrm{V}_{\mathrm{c}}$ a característica nuclear e para todas as outras a função de coda. A informação a respeito da posição exata do núcleo silábico seria obtida pela análise da máscara CVS da sílaba, o que pode ser feito posteriormente, caso se verifique útil o retorno de tal informação.

\section{IMPLEMENTAÇÃO COMPUTACIONAL}

Com base em todas as informações lingüísticas expressas anteriormente, já tínhamos em mão o algoritmo computacional propriamente dito, restava apenas implementá-lo. Optamos em um primeiro momento por implementá-lo em Matlab, do qual o laboratório da Unicamp dispunha de uma licença da versão completa, além das facilidades de depuração oferecidas por esta linguagem de programação.

O fluxograma computacional de nosso programa, após implementação, ficou da seguinte forma, conforme podemos observar na figura 2, a qual mostra também, para fins de comparação, o fluxograma computacional da versão do programa para VV. Na 
concepção do programa, a coda e o ataque são componentes consonantais e o núcleo, o componente vocálico.

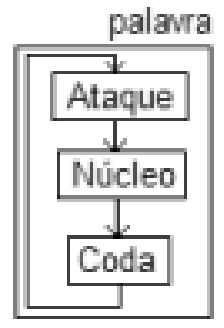

silaba

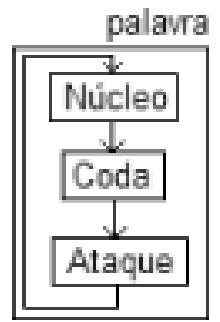

VV

Figura 2: Fluxograma de análise das sílabas e VVs da palavra

Após a elaboração do programa em Matlab, a fim de disponibilizar o programa pela Internet, no site do laboratório, e a fim de conseguir um baixo custo computacional, o programa foi traduzido para a linguagem $\mathrm{C}$, a qual possibilitava um desempenho muito rápido, e, posteriormente, para a linguagem PHP (http:// www.php.net/), que é uma linguagem mista, ou seja, possui tanto as características estruturais de $\mathrm{C}$ quanto possibilita todos os recursos da linguagem HTML para uma interface Web. Essa ferramenta está completamente depurada e publicada no endereço: http:// www.lafape.iel.unicamp.br/silWeb/index.php

Essa apresentação não corresponde à sua utilização no banco de dados, funcionando apenas como uma interface para testes do próprio programa em sua fase de depuração. O programa, no banco de dados, fornece as mesmas informações que poderão ser recuperadas em tabelas gravadas como arquivos de texto e, assim, passíveis de utilizações as mais diversas pelos pesquisadores. Além disso, é o programa SilWeb que possibilita buscas avançadas no banco de dados, com determinação da tonicidade da sílaba, da palavra, do número de sílabas e das máscaras CVS.

A utilização da ferramenta no referido site requer conhecimento da escrita do Ortofon, de cuja transcrição se pode obter algumas amostras no site: http://www.lafape.iel.unicamp.br/OrtofonWeb/. A 
escrita ortográfica, na maioria dos casos, incorrerá em erro, tal como em "antena", que resultará [oxítona], pois o último "a" seria escrito pelo Ortofon como reduzido (A) e, conseqüentemente, errando o número de pretônicas e postônicas. Além disso, a silabificação também resultaria errada: $a$-nte-na, pois o /n/ de coda deveria ser transcrito maiúsculo. Finalmente, embora com esses ajustes o resultado de tonicidade da palavra e número de sílabas resulte correto, a tonicidade da sílaba tônica só seria detectada com a presença do apóstrofo fornecido pelo programa Ortofon. Assim, a palavra "antena" deverá ser transcrita como "aNte'nA" para ser devidamente analisada pelo SilWeb. Observe-se na figura 3 o resultado da análise pelo SilWeb da palavra "escaldante" devidamente transcrita pelo Ortofon (/eSkaLda'NtI/).

\section{SilWeb}

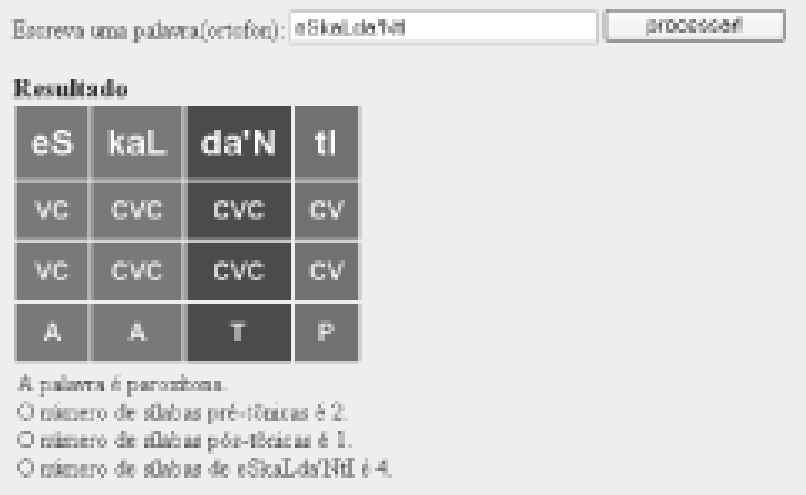

Figura 3: Exemplo do SilWeb com a palavra "escaldante" 


\section{SILWEB E SILWEBW, DIFERENÇAS E SEMELHANÇAS}

Como a unidade V-V é uma unidade prosódica e é consenso entre os lingüistas que a menor unidade prosódica é a sentença, a implementação do SilwebVV exigiu ter como entrada não mais a palavra, mas a sentença.

Tomemos como exemplo a sentença "O cais é belo". No caso da divisão silábica tradicional temos, já na escrita do Ortofon:

$$
\mathrm{o}-\mathrm{kaIS} \text { - eh - beh - } 1 \mathrm{O} \text {. }
$$

A divisão por unidades $\mathrm{V}-\mathrm{V}$ seria:

$$
\text { ok - aIS - ehb - ehl - O. }
$$

Observe-se que, enquanto a divisão silábica tem suas unidades determinadas dentro de cada palavra, na divisão por unidades $\mathrm{V}-\mathrm{V}$ as consoantes iniciais de cada uma fazem parte da última unidade $\mathrm{V}-\mathrm{V}$ da palavra que a antecede, por isso a entrada por palavras incorreria em diversos erros ou omissões.

Tendo em vista a organização extremamente coesa e lingüisticamente embasada do programa, assim como uma programação estruturada coerentemente com essas premissas, a implementação do SilWebVV não requer maiores discussões, pois consiste unicamente em deslocar o bloco de análise do ataque silábico para o final da seqüência, o que vai incorrer em poucas adaptações do programa original. Não cabe, porém, discutir esse procedimento no escopo do presente artigo. Tal deslocamento pode ser observado no fluxograma da figura 2.

\section{CONCLUSÃO}

Não é de hoje que o relacionamento aberto entre a lingüística e a engenharia produz resultados importantes para um, outro ou ambos os lados. No entanto, ainda é preciso enfrentar uma dificuldade de aceitação mútua: o trabalho da engenharia estaria estritamente voltado para aplicações práticas, de cunho tecnológico, enquanto os estudos lingüísticos seriam voltados à pesquisa de base e, portanto, pouco praticáveis no mundo da competitividade de mercado. 
Uma melhor instrumentalização do trabalho do lingüista, com aparatos como o SilWeb, Ortofon e o Aiuruetê, vem trazendo notáveis avanços na área, inclusive em termos de uma maior competitividade intra-área, com a pesquisa internacional, e interáreas, no mercado tecnológico. Assim, a cooperação mútua mostra-se extremamente profícua, cabendo enfatizar que não se trata de colocar uma área a serviço da outra, mas de uma efetiva troca de conhecimentos, como aquela da qual resultaram o SilWeb e o SilWebVV.

A ferramenta descrita no presente trabalho, o SilWeb, é um exemplo do sucesso dessa cooperação. O programa pode ser definido como uma ferramenta auxiliar para opções avançadas em buscas de palavras em corpus de grandes dimensões a partir da análise dos componentes fonológicos (máscaras CV e CVS) e da acentuação lexical da palavra, isolada ou em seqüência. Se, por um lado, um mínimo de regras de análise computacional foi obtido a partir do estudo fonológico da estrutura da sílaba no PB, por outro lado, o estudo utilizando uma metodologia de projeto orientado a objetos, mesmo não tendo sido levado às últimas conseqüências, permitiu o aproveitamento máximo da estrutura necessária de regras, retornando mais informações a respeito da palavra fonológica do que as inicialmente perseguidas. Além disso, a organização interna baseada em regras fonológicas permitiu a imediata adequação da ferramenta à unidade $\mathrm{V}-\mathrm{V}$, tão cara aos estudos prosódicos atuais.

\section{REFERÊNCIAS BIBLIOGRÁFICAS}

ALBANO, Eleonora C.; MOREIRA, A. A. Archisegment-based letter-to-phone conversion for concatenative speech synthesis in Portuguese. Proceedings ICSLP'96, v.3, p.1708-1711, 1996.

BARBOSA, Plínio A. At Least two macro rhythmic units are necessary for modeling Brazilian Portuguese duration: emphasis on segmental duration generation. Cadernos de Estudos Lingüisticos, 31, p. 33-53, 1996.

BISOL, Leda. Introdução a estudos de fonologia do português. 3. ed. Porto Alegre: EDIPUCRS, 1996. 
CAGLIARI, Luiz Carlos. Acento em português. Campinas: Edição do Autor, 1999. (Série Lingüística. V. 4.)

CALlOU, Dinah; LEITE, Yonne. Iniciação à fonética e à fonologia. Rio de Janeiro: Ed. Jorge Zahar Editor, 1990.

CÂMARA JR, J. M. Estrutura da Lingua Portuguesa. 12. ed. Petrópolis: Vozes, 1982 [1ํㅡㄹ ed.: 1970].

CRISTÓFARO-SILVA, Thaïs. Fonética e fonologia do português: roteiro de estudos e guia de exercícios. São Paulo: Contexto, 1999.

JESPERSEN, Otto. Lebrbuch der Phonetik. Trad. Hermann Davidson a partir do dinamarquês. Leipzig \& Berlin: B. G. Teubner, 1904.

MARCUS, Stephen Michael. Acoustic determinants of perceptual center (Pcenter) location. Perception \& Psychophysics 30 (30), p. 247-256, 1981. 